\title{
Post-discharge management following hip fracture - get you back to B4: A parallel group, randomized controlled trial study protocol
}

Wendy L Cook 1,2,3,4, Karim M Khan 1,2,5,6, Michelle H Bech ${ }^{4}$, Penelope M Brasher ${ }^{2,7}$, Roy A Brown ${ }^{4}$, Stirling Bryan²,7,8, Meghan G Donaldson 1,2, Pierre Guy ${ }^{1,2,9}$, Heather M Hanson 1,2,5, Cheryl Leia ${ }^{2,10}$, Erin M Macri ${ }^{1,2,5}$, Joanie Sims-Gould ${ }^{1,2,5}$, Heather A McKay ${ }^{1,2,5,9}$ and Maureen C Ashe ${ }^{1,2,5^{*}}$

\begin{abstract}
Background: Fall-related hip fractures result in significant personal and societal consequences; importantly, up to half of older adults with hip fracture never regain their previous level of mobility. Strategies of follow-up care for older adults after fracture have improved investigation for osteoporosis; but managing bone health alone is not enough. Prevention of fractures requires management of both bone health and falls risk factors (including the contributing role of cognition, balance and continence) to improve outcomes.
\end{abstract}

Methods/Design: This is a parallel group, pragmatic randomized controlled trial to test the effectiveness of a postfracture clinic compared with usual care on mobility for older adults following their hospitalization for hip fracture. Participants randomized to the intervention will attend a fracture follow-up clinic where a geriatrician and physiotherapist will assess and manage their mobility and other health issues. Depending on needs identified at the clinical assessment, participants may receive individualized and group-based outpatient physiotherapy, and a home exercise program. Our primary objective is to assess the effectiveness of a novel post-discharge fracture management strategy on the mobility of older adults after hip fracture.

We will enrol 130 older adults (65 years+) who have sustained a hip fracture in the previous three months, and were admitted to hospital from home and are expected to be discharged home. We will exclude older adults who prior to the fracture were: unable to walk 10 meters; diagnosed with dementia and/or significant comorbidities that would preclude their participation in the clinical service.

Eligible participants will be randomly assigned to the Intervention or Usual Care groups by remote allocation. Treatment allocation will be concealed; investigators, measurement team and primary data analysts will be blinded to group allocation. Our primary outcome is mobility, operationalized as the Short Physical Performance Battery at 12 months. Secondary outcomes include frailty, rehospitalizations, falls risk factors, quality of life, as well as physical activity and sedentary behaviour. We will conduct an economic evaluation to determine health related costs in the first year, and a process evaluation to ascertain the acceptance of the program by older adults, as well as clinicians and staff within the clinic.

Trial registration number: ClinicalTrials.gov: NCT01254942

\section{Background}

Hip fractures are serious, life-limiting and costly events for older adults. Each year in Canada there are over 27,000 hip fractures [1], and older adults who sustain a low-trauma hip fracture have higher risk of death and

\footnotetext{
* Correspondence: Maureen.Ashe@exchange.ubc.ca

${ }^{1}$ Centre for Hip Health and Mobility, Vancouver, Canada

Full list of author information is available at the end of the article
}

disability. In the first year after the fracture, as many as $20 \%$ of people die [2]; and up to half of seniors will not regain their pre-fracture level of mobility $[3,4]$ leaving them at risk for further falls [5] and fracture injuries [6-9]. Therefore, despite advances in surgical and medical management following hip fracture, up to half of hip fracture patients do not regain their independence or return to prefracture functional mobility.

\section{C) Biomed Central}

(c) 2011 Cook et al; licensee BioMed Central Ltd. This is an Open Access article distributed under the terms of the Creative Commons Attribution License (http://creativecommons.org/licenses/by/2.0), which permits unrestricted use, distribution, and reproduction in any medium, provided the original work is properly cited. 
After hip fracture, systematic structured follow-up strategies for older adults $[10,11]$ improve investigation rates for osteoporosis; and fracture liaison services [10-23] after fracture are beneficial. Many previous interventions, however, have focused on bone health management, and to our knowledge only a few studies $[18,20]$ have included patient referral for falls risk assessment. Osteoporosis care can be improved, but as fractures occur because of low bone mass and falls, it is important to also address falls risk [24]. It is noteworthy that despite being prescribed osteoporosis medication [11] some patients who attended a fracture liaison service had a subsequent fall-related low trauma fracture. Hence, the need to coordinate both falls prevention and bone health initiatives [11].

Ferrucci and colleagues [25] discuss that hip fracture can result in "catastrophic disability" for older adults due to the unanticipated deterioration in functional ability [25] in some activities of daily living and mobility. Decreased mobility, in turn, impacts on the risk for future injury. Importantly, older adults who sustain hip fracture are at an increased risk of future hip fracture [26,27]. A systematic review [8] emphasized that previous falls [28], low bone density [28,29], and mobility impairment [28] are major risk factors for second hip fracture. Approximately $90 \%$ of fractures occur as a result of a fall [30] and after hip fracture, up to half of people can fall again within the first 6 months following fracture [5,31]. These data emphasise the importance of a two-pronged approach to reducing hip fractures - addressing falls risk as well as low bone mass [32].

Compelling evidence supports the recommendation for strength and balance exercises for falls risk reduction in vulnerable populations [33-36]. Exercise improves lower limb muscle strength and it can maintain bone mass in post-menopausal women [37-39]. A Cochrane systematic review [40] reported six trials that evaluated exercise interventions for people after hospital discharge following hip fracture. Balance and strength measures improved overall; in particular, Binder and colleagues [41] reported a significant improvement in mobility measures after a six month out-patient physical therapy intervention.

Therefore, the purpose of the current study is to evaluate the clinical and cost effectiveness of a novel postdischarge fracture management strategy for communitydwelling older adults after hip fracture. It is anticipated that initiating an individualized outpatient management program after hospital discharge, which includes falls and fracture risk assessment and management, and an individualized exercise program under the ongoing guidance of a physical therapist, will improve mobility, and reduce disability and falls.

\section{Methods/design \\ Study Aims}

The primary aim of this study is to assess the effectiveness of a comprehensive post-fracture clinic with extended rehabilitation for community-dwelling older adults following hip fracture on mobility. Secondary aims include prospectively (i) determining costs associated with hip fracture, and our intervention, and (ii) completing a process evaluation as part of our integrated knowledge translation plan.

\section{Study Design and Setting}

We propose a parallel group, pragmatic [42] single blind randomized controlled trial of two different delivery modes of post hip fracture management- Usual Care alone versus Usual Care plus specialized outpatient fracture follow-up management. This study will take place at two academic teaching hospitals in Vancouver, Canada. Vancouver is the largest city in the province of British Columbia and with an estimated population of 578,000 and $13 \%$ of the population are adults aged 65 years+ (2006 Census Data; http://vancouver.ca/ commsvcs/planning/census/2006/index.htm). Our clinic is located within the Vancouver Coastal Health Authority (VCHA) catchment area.

\section{Ethical Approval}

We have obtained ethical approval from the University of British Columbia (UBC) Clinical Research Ethics Board, Vancouver Coastal Health Research Institute Ethics Board, and Providence Health Ethics Board. All participants will provide written informed consent prior to participating in the study (Clinical Trials Registration NCT01254942).

\section{Participants}

We will include 130 community-dwelling older adults (women and men) aged 65 years+ who, with a recent history (within past 3 months) of hip fracture, were admitted to hospital from home and expected to be discharged home. We will exclude older adults who prior to the fracture were: unable to walk 10 meters; diagnosed with dementia; and/or with significant comorbidities that would preclude their participation in the clinical service.

\section{Identification of Eligible Participants}

Our recruitment coordinator will identify and enrol patients into the study prior to discharge from hospital, rehabilitation unit and/or from a discharge list of eligible older adults. Identification of potential participants will be facilitated by the clinical staff; in addition, recruitment posters will also be placed on the ward and on the Centre for Hip Health and Mobility website. The recruitment coordinator will provide written and verbal information to all eligible participants. 


\section{Randomization}

Treatment allocation will be concealed; a statistician independent of the study will generate the allocation sequence using randomized blocks of varying size; we will stratify randomization by hospital site and sex. This list will be provided to a centralized, web-based randomization service. At the completion of the baseline assessment the study coordinator will use the online service to determine the next allocation. Investigators, the measurement team and data analysts will be blinded to group assignment throughout the trial (Flow Diagram in Figure 1).

\section{Study Interventions}

Usual Care (UC) group Participants who are randomized to the UC Group will receive usual orthopaedic and rehabilitation post-operative treatment for the hip fracture. Participants in the UC Group will be offered the Fracture Follow-up Clinic at 12 months (please see below for description).

Intervention (B4) group Participants who are randomized to this group will attend an enhanced post-fracture follow-up clinic for outpatient management of falls

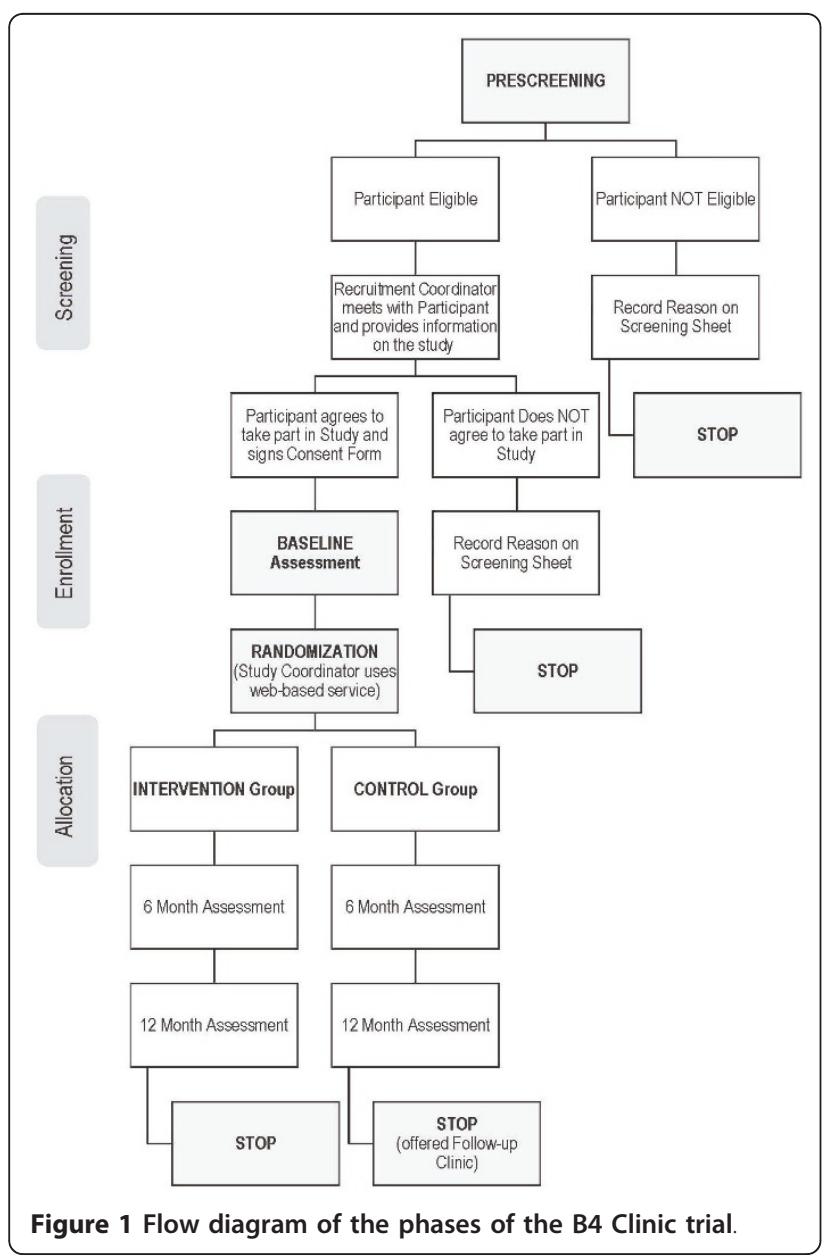

and fracture risk. The clinic has been designed based on the need to assess both falls risk factors and bone health. A geriatrician will lead the clinic and will provide post-fracture assessment and management. The clinical assessment will focus on four key areas to address secondary prevention of future injury by addressing key domains that contribute to fall and fracture risk, and include assessment of: balance, bone health, brain function and bladder function = B4 Clinic. Based on identified need during the geriatric assessment, participants may also be referred to additional health professionals such as occupational therapist, registered dietician, social worker etc.

In addition, while at the clinic, participants will also be assessed by a physiotherapist who will recommend an exercise program and, may recommend subsequent onsite outpatient physiotherapy visits. Participants will also receive a standardized home exercise program. Following discharge from outpatient physiotherapy, participants will also receive up to four additional telephone calls based on motivational interviewing [43], and we will use techniques to problem solve and facilitate goal setting around mobility and regular engagement in physical activity. If during these sessions, the participant identifies a mobility concern, she/he will be encouraged to follow-up with the B4 Clinic.

\section{Outcomes}

Data Collection Protocol

Measurements will be conducted at the Centre for Hip Health and Mobility, Vancouver Coastal Heath Research Institute on the Vancouver General Hospital site or at a participant's home at baseline (3 months post-surgical repair), 6 and 12 months.

\section{Primary Outcome}

Our primary outcome for this trial is mobility as measured by the Short Physical Performance Battery (SPPB) at 12 months. This valid and reliable measure of mobility has been developed with older adults to assess balance and other key lower extremity functions [44]. The SPPB is composed of three separate tests that are timed and categorized depending on performance: the tests include standing balance, gait speed and sit to stand performance. The SPPB can predict future disability in older adults [45].

\section{Secondary Health Outcomes Mobility Measures}

We will use: (i) the Lower Extremity Measure Scale (LEM) [46], a valid and reliable self-report measure developed specifically for people after hip fracture to assess functional status and to distinguish clinically important change over time [46]; and (ii) the Timed Up and Go (TUG) Test [47] to assess basic mobility 
function related to transfers, balance and walking capacity. An objective measure of leg strength will be collected.

Falls will be measured by self-reported daily fall diaries, which will be completed and reported monthly to study investigators and followed up by an independent investigator. We will also use the QuickScreen to characterize components of falls risk. This 10 minute test measures key components of falls risk [48] including performance based measures (standing balance, coordination, vision, lower extremity sensation and sit-stands) and self-report information on previous falls and medications. We will assess falls-related self-efficacy by the Short-form Falls Efficacy Scale-International [49].

\section{Frailty}

We will collect information related to the participants' degree of frailty using two methods: the Clinical Frailty Scale [50], and a frailty index from Fried and colleagues derived from our study measures [51].

\section{Patterns of Physical Activity and Sedentary Behaviour}

Once a month we will ask participants to complete a Community Healthy Activities Model Program for Seniors (CHAMPS) questionnaire, a valid and reliable 7day recall self-report tool [52]. We will also ask participants to wear an accelerometer at three time points (baseline, 6 and 12 months) to objectively measure physical activity and sedentary behaviour patterns.

\section{Bone Health}

We will record the number of best practice bone health options (i) offered and (ii) utilized by all participants, using a list generated from the 2010 Canadian clinical practice guidelines [53] for diagnosis and management of osteoporosis.

\section{Cognitive Performance}

We will assess global cognition with the Montreal Cognitive Assessment (MoCA) [54] and components of executive function using the Trail Making (Part B) [55] and Stroop Colour Word Tests [56].

\section{Continence}

Urge incontinence is a risk factor for falls [57,58], and will be ascertained via screening questions [59].

\section{Descriptive Data}

\section{Hospital Medical Chart Review}

We will collect information regarding previous hospital admissions; participants' health status prior to the hip fracture and at discharge, any complications during hospitalization for the hip fracture repair and the number of inpatient visits by physical and occupational therapists and related information. We will also check for any falls that participants may have while in hospital. In addition, we will record assessments of the four research areas (balance, bone health, cognition and continence) and physical therapy management that occurs as part of the B4 Clinic.

\section{Descriptive Information}

We will capture date of birth, sex, marital status, height and weight. Body mass index will be calculated as weight $(\mathrm{kg}) /$ height $\times$ meters $^{2}$. The Functional Comorbidity Index will be used to estimate comorbidities associated with physical functioning [60]. We will determine pre-fracture function during the week prior to fracture; and will screen for depression [61], and monitor pain and fatigue [62].

\section{Quality of Life and Health Resource Utilization Measures}

We will use the EQ-5D-5L, a generic health related quality of life measure [63]. This five question measure is easy to administer and can be used in cost-effectiveness studies to evaluate clinical interventions [63]. Respondents are asked to rate their health states for mobility, self-care, usual activities, pain/discomfort and anxiety/depression. We will use a capability measure, the ICECAP-O [64] to determine the effect of the intervention on participants' quality of life. We will also use a modified health resource utilization questionnaire [65] to capture self-report direct and indirect costs.

\section{Process Evaluation}

We will use a $\log$ to record all eligible participants and will document reasons for ineligibility or refusal to participate. Adherence to the B4 Clinic will be monitored over the course of the intervention, and adverse events monitoring will occur throughout the study. We will invite participants to complete an exit interview to examine satisfaction with components of the intervention. We will also explore barriers and enablers to participation in the Clinic services; and specifically we will examine reasons for low attendance. Finally we will complete open-ended qualitative interviews with clinical and research staff throughout the study to document our progress. Members of the research team will review the findings from these interviews and adjust research administrative procedures if necessary and appropriate.

\section{Statistical Analysis \\ Sample Size}

We plan to recruit 130 participants over an 18-month period. Allowing for $15 \%$ loss to follow-up we will have 110 evaluable participants at 12 months. We have chosen to power the study to detect fairly large effect sizes as the proposed intervention represents an intensive use of scarce resources (geriatrician, physical therapists) and would need to demonstrate large effects to be considered for adoption by health funders. Justification for sample size: Given the anticipated presence of ceiling and/or floor effects in the SPPB we will compare the two groups, without adjusting using a Wilcoxon-MannWhitney (WMW) test. The WMW test can be 
characterized by the WMW odds ratio, $\mathrm{OR}_{\mathrm{wmw}}=\pi /(1-$ $\pi)$ where $\pi=\operatorname{Pr}\left(Y_{1}<Y_{2}\right)+0.5 \operatorname{Pr}\left(Y_{1}=Y_{2}\right)$. Note, if there is no difference between the groups, $\pi=0.5$ or equivalently, $\mathrm{OR}_{\mathrm{wmw}}=1.0$. If the $\mathrm{OR}_{\mathrm{wmw}}$ is 2.0 , the odds are 2:1 that $Y_{1}$ is less than $Y_{2}$, i.e. $\pi=2 / 3$. With 55 evaluable participants/group we will have $>80 \%$ power to detect ORs of 2.0 or greater assuming $\alpha=0.05$ (2sided) [66].

\section{Primary analysis}

All analyses will be intention-to-treat; there will be no interim analysis. SPPB at 12 months post randomization will be compared between the two groups using the Wilcoxon-Mann-Whitney test. Point and interval estimates for the difference in medians will be calculated.

\section{Secondary analyses}

All secondary analyses will be for descriptive purposes only. Point and interval estimates of the effect of the intervention on LEM scores at 6 and 12 months will be determined using a linear mixed model. The baseline LEM score will be included in the model as a covariate. Analyses for frailty, TUG and activity patterns as measured by CHAMPS and accelerometry will follow that of LEM. Types of management received and adherence to prescribed therapies will be described separately for each group. Analyses will be conducted at 6 months for descriptive purposes only.

\section{Discussion}

We have adopted the Integrated Knowledge Translation model for this project. We recognize the need for postdischarge hip fracture management and have worked together with clinicians to develop this model. Our preliminary work included interviews with seniors to pilot our outcome measures and better understand barriers and enablers to taking part in exercise after hip fracture. In addition, our team includes knowledge users such as our partners within the local health authority, and clinicians who work daily with this population. We have previously shown effectiveness of our falls clinic model [67] and now extend this work with a higher risk population. We aim to test a delivery model that would be acceptable to both older adults, their caregivers and clinicians; and will complete an economic evaluation in parallel to determine operating costs and cost-effectiveness and cost-utility of the intervention.

\footnotetext{
Acknowledgements

The B4 Research Team would like to thank all the clinicians and staff at St. Paul's Hospital and Vancouver Acute Hospital for their support and expert guidance in the development of this trial. In addition, we would also like to thank staff and colleagues at the Centre for Hip Health and Mobility for ongoing support and development of this project. We are grateful to the Canadian Institutes of Health Research (CIHR) for operational support (CIHR DPA - 99051) of this study and the New Investigator Award (MCA). We would also like to acknowledge the St. Paul's Hospital Foundation for salary
}

support (WLC) and the Michael Smith Foundation for Health Research (MSFHR) for Career Award support (MCA). Finally, we would also like to acknowledge the support of the British Columbia Network for Aging Research who provided early funds to investigate older adults' recovery processes that formed the basis for this research program.

\section{Author details}

${ }^{1}$ Centre for Hip Health and Mobility, Vancouver, Canada. ${ }^{2}$ Vancouver Coastal Health Research Institute, Vancouver, Canada. ${ }^{3}$ Department of Medicine, University of British Columbia, Vancouver, Canada. ${ }^{4}$ Providence Health Care, Vancouver, Canada. ${ }^{5}$ Department of Family Practice, University of British Columbia, Vancouver, Canada. ${ }^{6}$ School of Human Kinetics, University of British Columbia, Vancouver, Canada. ${ }^{7}$ Centre for Clinical Epidemiology and Evaluation, Vancouver, Canada. ${ }^{8}$ School of Population and Public Health, University of British Columbia, Vancouver, Canada. ${ }^{9}$ Department of Orthopaedics, University of British Columbia, Vancouver, Canada.

${ }^{10}$ Vancouver Coastal Health Authority, Vancouver, Canada.

\section{Authors' contributions}

WLC, KMK, PB, PG, HAM, and MCA contributed to the research question development and drafting the study protocol. $M B, R A B, S B, M G D, H M H, C L$, EMM, and JSG contributed to the development of the study protocol and dissemination plan design. WLC and MCA were responsible for drafting this publication, with significant contribution from KMK and HAM. All team members provided input to this manuscript and approved the final version.

\section{Competing interests}

The authors declare that they have no competing interests.

Received: 6 February 2011 Accepted: 9 June 2011

Published: 9 June 2011

\section{References}

1. Wiktorowicz ME, Goeree R, Papaioannou A, Adachi JD, Papadimitropoulos E: Economic implications of hip fracture: health service use, institutional care and cost in Canada. Osteoporos Int 2001, 12(4):271-278.

2. Braithwaite RS, Col NF, Wong JB: Estimating hip fracture morbidity, mortality and costs. J Am Geriatr Soc 2003, 51(3):364-370.

3. Eastwood EA, Magaziner J, Wang J, Silberzweig SB, Hannan EL, Strauss E, Siu AL: Patients with hip fracture: subgroups and their outcomes. J Am Geriatr Soc 2002, 50(7):1240-1249.

4. Penrod JD, Litke A, Hawkes WG, Magaziner J, Koval KJ, Doucette JT, Silberzweig SB, Siu AL: Heterogeneity in hip fracture patients: age, functional status, and comorbidity. J Am Geriatr Soc 2007, 55(3):407-413.

5. Shumway-Cook A, Ciol MA, Gruber W, Robinson C: Incidence of and risk factors for falls following hip fracture in community-dwelling older adults. Phys Ther 2005, 85(7):648-655.

6. Berry SD, Samelson EJ, Hannan MT, McLean RR, Lu M, Cupples LA, Shaffer ML, Beiser AL, Kelly-Hayes M, Kiel DP: Second hip fracture in older men and women: the Framingham Study. Arch Intern Med 2007, 167(18):1971-1976.

7. Chapurlat RD, Bauer DC, Nevitt M, Stone K, Cummings SR: Incidence and risk factors for a second hip fracture in elderly women. The Study of Osteoporotic Fractures. Osteoporos Int 2003, 14(2):130-136.

8. Egan M, Jaglal S, Byrne K, Wells J, Stolee P: Factors associated with a second hip fracture: a systematic review. Clin Rehabil 2008, 22(3):272-282.

9. Nymark T, Lauritsen JM, Ovesen O, Rock ND, Jeune B: Short time-frame from first to second hip fracture in the Funen County Hip Fracture Study. Osteoporos Int 2006, 17(9):1353-1357.

10. Majumdar SR, Beaupre LA, Harley CH, Hanley DA, Lier DA, Juby AG, Maksymowych WP, Cinats JG, Bell NR, Morrish DW: Use of a case manager to improve osteoporosis treatment after hip fracture: results of a randomized controlled trial. Arch Intern Med 2007, 167(19):2110-2115.

11. Langridge CR, McQuillian C, Watson WS, Walker B, Mitchell L, Gallacher SJ: Refracture following fracture liaison service assessment illustrates the requirement for integrated falls and fracture services. Calcif Tissue Int 2007, 81(2):85-91.

12. Hawker G, Ridout R, Ricupero M, Jaglal S, Bogoch E: The impact of a simple fracture clinic intervention in improving the diagnosis and treatment of osteoporosis in fragility fracture patients. Osteoporos Int 2003, 14(2):171-178. 
13. Majumdar SR, Lier DA, Beaupre LA, Hanley DA, Maksymowych WP, Juby AG, Bell NR, Morrish DW: Osteoporosis case manager for patients with hip fractures: results of a cost-effectiveness analysis conducted alongside a randomized trial. Arch Intern Med 2009, 169(1):25-31.

14. Miki RA, Oetgen ME, Kirk J, Insogna KL, Lindskog DM: Orthopaedic management improves the rate of early osteoporosis treatment after hip fracture. A randomized clinical trial. J Bone Joint Surg Am 2008, 90(11):2346-2353.

15. Ward SE, Laughren JJ, Escott BG, Elliot-Gibson V, Bogoch ER, Beaton DE: A program with a dedicated coordinator improved chart documentation of osteoporosis after fragility fracture. Osteoporos Int 2007, 18(8):1127-1136

16. Quintos-Macasa AM, Quinet R, Spady M, Zakem J, Davis W, Menon Y, Serebro L, Krousel-Wood MA: Implementation of a mandatory rheumatology osteoporosis consultation in patients with low-impact hip fracture. J Clin Rheumatol 2007, 13(2):70-72.

17. Blonk MC, Erdtsieck RJ, Wernekinck MG, Schoon EJ: The fracture and osteoporosis clinic: 1-year results and 3-month compliance. Bone 2007, 40(6):1643-1649

18. van Helden S, Cals J, Kessels F, Brink P, Dinant GJ, Geusens P: Risk of new clinical fractures within 2 years following a fracture. Osteoporos Int 2006, 17(3):348-354.

19. Bogoch ER, Elliot-Gibson V, Beaton DE, Jamal SA, Josse RG, Murray TM: Effective initiation of osteoporosis diagnosis and treatment for patients with a fragility fracture in an orthopaedic environment. J Bone Joint Surg Am 2006, 88(1):25-34.

20. Wright SA, McNally C, Beringer T, Marsh D, Finch MB: Osteoporosis fracture liaison experience: the Belfast experience. Rheumatol Int 2005, 25(6):489-490.

21. McLellan AR, Gallacher SJ, Fraser M, McQuillian C: The fracture liaison service: success of a program for the evaluation and management of patients with osteoporotic fracture. Osteoporos Int 2003, 14(12):1028-1034.

22. Chevalley T, Hoffmeyer P, Bonjour JP, Rizzoli R: An osteoporosis clinical pathway for the medical management of patients with low-trauma fracture. Osteoporos Int 2002, 13(6):450-455.

23. Murray AW, McQuillan C, Kennon B, Gallacher SJ: Osteoporosis risk assessment and treatment intervention after hip or shoulder fracture. A comparison of two centres in the United Kingdom. Injury 2005, 36(9):1080-1084

24. Jarvinen $T L$, Sievanen $H$, Khan KM, Heinonen A, Kannus P: Shifting the focus in fracture prevention from osteoporosis to falls. Bmj 2008, 336(7636):124-126.

25. Ferrucci L, Guralnik JM, Simonsick E, Salive ME, Corti C, Langlois J: Progressive versus catastrophic disability: a longitudinal view of the disablement process. J Gerontol A Biol Sci Med Sci 1996, 51(3):M123-130.

26. Schroder HM, Petersen KK, Erlandsen M: Occurrence and incidence of the second hip fracture. Clin Orthop Relat Res 1993, , 289: 166-169.

27. Wolinsky FD, Fitzgerald JF: Subsequent hip fracture among older adults. Am J Public Health 1994, 84(8):1316-1318.

28. Stewart A, Walker LG, Porter RW, Reid DM, Primrose WR: Predicting a second hip fracture. Journal of Clinical Densitometry 1999, 2:363-370.

29. RD C, Bauer DC, Nevitt MC, Stone K, Cummings SR: Incidence and risk factors for a second hip fracture in elderly women. The Study of Osteoporotic Fractures. Osteoporos Int 2003, 14(2):130-136.

30. Nevitt MC, Cummings SR: Type of fall and risk of hip and wrist fractures: the study of osteoporotic fractures. The Study of Osteoporotic Fractures Research Group. J Am Geriatr Soc 1993, 41(11):1226-1234.

31. Kristensen MT, Foss NB, Kehlet H: Timed "up \& go" test as a predictor of falls within 6 months after hip fracture surgery. Phys Ther 2007, 87(1):24-30.

32. Jarvinen $T L N$, Sievanen $H$, Khan KM, Heinonen A, Kannus P: Shifting the focus in fracture prevention from osteoporosis to falls. BMJ (Clinical research ed) 2008, 336:124-126.

33. Campbell AJ, Robertson MC, Gardner MM, Norton RN, Buchner DM: Falls prevention over 2 years: a randomized controlled trial in women 80 years and older. Age Ageing 1999, 28(6):513-518.

34. Campbell AJ, Robertson MC, Gardner MM, Norton RN, Tilyard MW, Buchner DM: Randomised controlled trial of a general practice programme of home based exercise to prevent falls in elderly women. Bmj 1997, 315(7115):1065-1069.
35. Gillespie LD, Gillespie WJ, Robertson MC, Lamb SE, Cumming RG, Rowe BH: Interventions for preventing falls in elderly people. Cochrane Database Syst Rev 2003, , 4: CD000340.

36. Sherrington C, Whitney JC, Lord SR, Herbert RD, Cumming RG, Close JC: Effective exercise for the prevention of falls: a systematic review and meta-analysis. J Am Geriatr Soc 2008, 56(12):2234-2243.

37. Martyn-St James M, Carroll S: High-intensity resistance training and postmenopausal bone loss: a meta-analysis. Osteoporos Int 2006, 17(8):1225-1240.

38. Wallace BA, Cumming RG: Systematic review of randomized trials of the effect of exercise on bone mass in pre- and postmenopausal women. Calcif Tissue Int 2000, 67(1):10-18.

39. Wolff I, van Croonenborg JJ, Kemper HC, Kostense PJ, Twisk JW: The effect of exercise training programs on bone mass: a meta-analysis of published controlled trials in pre- and postmenopausal women. Osteoporos Int 1999, 9(1):1-12.

40. Handoll HH, Sherrington C: Mobilisation strategies after hip fracture surgery in adults. Cochrane Database Syst Rev 2007, , 1: CD001704.

41. Binder EF, Brown M, Sinacore DR, Steger-May K, Yarasheski KE, Schechtman KB: Effects of extended outpatient rehabilitation after hip fracture: a randomized controlled trial. Jama 2004, 292(7):837-846.

42. Hotopf M, Churchill R, Lewis G: Pragmatic randomised controlled trials in psychiatry. Br J Psychiatry 1999, 175:217-223.

43. Martins RK, McNeil DW: Review of Motivational Interviewing in promoting health behaviors. Clin Psychol Rev 2009, 29(4):283-293.

44. Guralnik JM, Simonsick EM, Ferrucci L, Glynn RJ, Berkman LF, Blazer DG, Scherr PA, Wallace RB: A short physical performance battery assessing lower extremity function: association with self-reported disability and prediction of mortality and nursing home admission. J Gerontol 1994 49(2):M85-94.

45. Guralnik JM, Ferrucci L, Simonsick EM, Salive ME, Wallace RB: Lowerextremity function in persons over the age of 70 years as a predictor of subsequent disability. N Engl J Med 1995, 332(9):556-561.

46. Jaglal S, Lakhani Z, Schatzker J: Reliability, validity, and responsiveness of the lower extremity measure for patients with a hip fracture. J Bone Joint Surg Am 2000, 82-A(7):955-962.

47. Shumway-Cook A, Brauer S, Woollacott M: Predicting the probability for falls in community-dwelling older adults using the Timed Up \& Go Test. Phys Ther 2000, 80(9):896-903.

48. Tiedemann A, Lord SR, Sherrington C: The development and validation of a brief performance-based fall risk assessment tool for use in primary care. J Gerontol A Biol Sci Med Sci 2010, 65(8):896-903.

49. Kempen Gl, Yardley L, van Haastregt JC, Zijlstra GA, Beyer N, Hauer K, Todd C: The Short FES-l: a shortened version of the falls efficacy scaleinternational to assess fear of falling. Age Ageing 2008, 37(1):45-50.

50. Jones DM, Song $X$, Rockwood $K$ : Operationalizing a frailty index from a standardized comprehensive geriatric assessment. J Am Geriatr Soc 2004, 52(11):1929-1933.

51. Fried LP, Tangen CM, Walston J, Newman AB, Hirsch C, Gottdiener J, Seeman T, Tracy R, Kop WJ, Burke G, et al: Frailty in older adults: evidence for a phenotype. J Gerontol A Biol Sci Med Sci 2001, 56(3):M146-156.

52. Stewart AL, Mills KM, Sepsis PG, King AC, McLellan BY, Roitz K, Ritter PL: Evaluation of CHAMPS, a physical activity promotion program for older adults. Ann Behav Med 1997, 19(4):353-361.

53. Papaioannou A, Morin S, Cheung AM, Atkinson S, Brown JP, Feldman S, Hanley DA, Hodsman A, Jamal SA, Kaiser SM, et al: 2010 clinical practice guidelines for the diagnosis and management of osteoporosis in Canada: summary. Cmaj 2010, 182(17):1864-1873.

54. Nasreddine ZS, Phillips NA, Bedirian V, Charbonneau S, Whitehead V, Collin I, Cummings JL, Chertkow H: The Montreal Cognitive Assessment, MoCA: a brief screening tool for mild cognitive impairment. J Am Geriatr Soc 2005, 53(4):695-699.

55. Nevitt MC, Cummings SR, Hudes ES: Risk factors for injurious falls: a prospective study. J Gerontol 1991, 46(5):M164-170.

56. Trenerry MR, Crosson B, DeBoe J, Leber WR: Stroop Neuropsychological Screening Test. Odessa, Fla.: Psychological Assessment Resources; 1989.

57. Pils K, Neumann F, Meisner W, Schano W, Vavrovsky G, Van der Cammen TJ: Predictors of falls in elderly people during rehabilitation after hip fracture-who is at risk of a second one? Z Gerontol Geriatr 2003, 36(1):16-22. 
58. Tromp AM, Smit JH, Deeg DJ, Bouter LM, Lips P: Predictors for falls and fractures in the Longitudinal Aging Study Amsterdam. J Bone Miner Res 1998, 13(12):1932-1939.

59. Gray M: The importance of screening, assessing, and managing urinary incontinence in primary care. J Am Acad Nurse Pract 2003, 15(3):102-107.

60. Groll DL, To T, Bombardier C, Wright JG: The development of a comorbidity index with physical function as the outcome. J Clin Epidemiol 2005, 58(6):595-602.

61. Yesavage $\mathrm{JA}$, Brink TL, Rose TL, Lum O, Huang V, Adey M, Leirer VO: Development and validation of a geriatric depression screening scale: a preliminary report. J Psychiatr Res 1982, 17(1):37-49.

62. Krupp LB, LaRocca NG, Muir-Nash J, Steinberg AD: The fatigue severity scale. Application to patients with multiple sclerosis and systemic lupus erythematosus. Arch Neurol 1989, 46(10):1121-1123.

63. Rabin R, de Charro F: EQ-5D: a measure of health status from the EuroQol Group. Ann Med 2001, 33(5):337-343.

64. Coast J, Flynn TN, Natarajan L, Sproston K, Lewis J, Louviere JJ, Peters TJ: Valuing the ICECAP capability index for older people. Soc Sci Med 2008, 67(5):874-882.

65. Maetzel A, Li LC, Pencharz J, Tomlinson G, Bombardier C: The economic burden associated with osteoarthritis, rheumatoid arthritis, and hypertension: a comparative study. Ann Rheum Dis 2004, 63(4):395-401.

66. Noether GE: Sample size determination for some common nonparametric tests. Journal of the American Statistical Association 1987, 82:645-647.

67. Liu-Ambrose T, Donaldson MG, Ahamed Y, Graf P, Cook WL, Close J, Lord SR, Khan KM: Otago home-based strength and balance retraining improves executive functioning in older fallers: a randomized controlled trial. J Am Geriatr Soc 2008, 56(10):1821-1830.

\section{Pre-publication history}

The pre-publication history for this paper can be accessed here: http://www.biomedcentral.com/1471-2318/11/30/prepub

doi:10.1186/1471-2318-11-30

Cite this article as: Cook et al: Post-discharge management following hip fracture - get you back to B4: A parallel group, randomized controlled trial study protocol. BMC Geriatrics 2011 11:30.

\section{Submit your next manuscript to BioMed Central and take full advantage of:}

- Convenient online submission

- Thorough peer review

- No space constraints or color figure charges

- Immediate publication on acceptance

- Inclusion in PubMed, CAS, Scopus and Google Scholar

- Research which is freely available for redistribution

Submit your manuscript at www.biomedcentral.com/submit
Biomed Central 